\title{
A POSSIBLE RELATION BETWEEN GRAIN SIZE, DENSITY, AND LIGHT ATTENUATION IN NATURAL SNOW COVER
}

\author{
By James D. Bergen \\ (U.S. Forest Service, Rocky Mountain Forest and Range Experiment Station,* Fort Collins, Colorado \\ 80521 , U.S.A.)
}

Abstract. The extinction coefficient for the transmission of light through snow cover is related to the grain size and density of the snow cover. The connection is made by means of an empirical relation between the latter parameters and the air permeability and by the Carmen-Kozney relation between the air permeability and specific surface of a porous medium. The results are compared with a set of measurements found in the literature with fair agreement between the predicted and measured values of the extinction coefficient.

Résumé. Une relation possible entre le grandeur des grains, la densite et l'attenuation de la lumière dans une couche de neige naturelle. Le coefficient d'extinction de la transmission de la lumière au travers d'une couche de neige a un rapport direct avec la densité de la couche de neige et la taille de la granulation. Le résultat est trouvé en se servant d'une relation empirique entre le paramètre de cette dernière et la perméabilité de l'air, et par la relation Carmen-Kozney entre la perméabilité de l'air et la surface spécifique d'une matière poreuse Les résultats comparés à un ensemble de mesurages trouvés dans le texte montreront un accord favorable entre ce qui a été prédit et les valeurs mesurées du coefficient d'extinction.

Zusammenfassung. Eine mögliche Beziehung zwischen Korngrösse, Dichte und Lichtabschwächung in natürlichen Schneedecken. Der Extinktionskoeffizient für den Durchgang von Licht durch eine Schneedecke wird mit deren Korngrösse und Dichte in Beziehung gebracht. Dies geschieht einerseits durch eine empirische Beziehung zwischen den genannten Parametern und der Luftdurchlässigkeit, anderseits durch die CarmenKozney-Beziehung zwischen der Luftdurchlässigkeit und Oberflächenstruktur eines porösen Mediums. Der Vergleich der Ergebnisse mit veröffentlichten Messungen zeigt eine befriedigende Übereinstimmung zwischen den berechneten und gemessenen Werten für den Extinktionskoeffizienten.

THE penetration of light into natural snow cover is of interest both to ecologists and those concerned with the thermodynamics of snow ablation and metamorphosis. An estimate of the optical extinction coefficient at a particular wavelength in terms of physical properties frequently measured in the fieldsuch as density and grain size - would often be of considerable utility. This note suggests a model for such an estimate.

The basic radiation transfer model applied to snow by Dunkle and Bevans (1956) is attributed to Schuster, and in its modified form to Schwartzchild. The same formal relations may be deduced from a variety of physical assumptions. A recent derivation by Kottler (1964) is briefly outlined below.

A slab of dispersed material is considered, of depth $\mathrm{d} x$ where $\mathrm{d} x$ is less than the average distance between adjacent reflecting surfaces in the medium. The parameters in the radiation balance will refer to average physical properties of the medium in the horizontal planes.

The slab is assumed to be thin enough so that only primary and secondary scattering need be considered. The latter is assumed to be "isotropic" in the sense that, if a pencil of light is scattered from a point $\mathrm{P}$ on a surface in the slab in the direction $\theta$ relative to the $x$-axis, the contributions to that pencil between $\mathrm{P}$ and the surface of the slab from secondary scattering from other pencils originating at $\mathrm{P}$ with various angles $\theta^{\prime}$ is independent of $\theta^{\prime}$.

If a forward flux $Y$ is defined as the integral over all values of $\theta$, taken in the forward sense on the $x$-axis, and a backward flux $Z$ is similarly defined for a negative sense, it may be shown that

$$
\begin{gathered}
\mathrm{d} Y=-k Y \mathrm{~d} x-r Y \mathrm{~d} x+r Z \mathrm{~d} x, \\
\mathrm{~d} Z=k Z \mathrm{~d} x-r Y \mathrm{~d} x+r Z \mathrm{~d} x,
\end{gathered}
$$

where $k$ is the average volume absorptivity of the medium for diffuse radiation and $r$, in the nomenclature of Dunkle and Bevans, is the "distributed reflectivity" of the medium.

If the differential balance equations above are integrated over a semi-infinite physically uniform slab, with diffuse illumination at $x=\mathrm{o}$,

where $\quad \beta=\left(k^{2}+2 k r\right)^{\mathrm{I} / 2}$.

If the variations in the radiation field in that plane may be neglected or are uncorrelated with the variations of grain size in the local medium structure, the absorptivity $k$ refers to the average absorptivity of the medium along a collection of straight-line segments drawn for a uniform random distribution of angles to the vertical axis. U.S.A.

* Central headquarters maintained in cooperation with Colorado State University, Fort Collins, Colorado, 
For a statistically homogeneous porous material, the average fraction of such segments which will lie in the solid phase will be $(\mathrm{I}-\eta)$, where $\eta$ is the absolute porosity (Fara and Scheidegger, $196 \mathrm{I})$. Thus, for the case of light with wavelength $\lambda$ in snow

$$
k=k_{\lambda}(\mathbf{I}-\eta)
$$

where $k_{\lambda}$ is the absorption coefficient for radiation of wavelength $\lambda$ of ice at the local snow temperature.

The reflectivity in a real snow cover must depend mainly on the area of ice-to-air interface $S$ per unit volume of the snow. Considered as an equivalent set of ice laminae, the ice-to-air surfaces would face in one of three directions relative to the incident ray; the effective reflecting surface would be $S / 3$; and if $r_{0}$ is the reflectivity of an ice-air interface at normal incidence,

$$
r=r_{0} S / 3 .
$$

The specific surface of a porous material has no self-evident relation to either grain size or density (Scheidegger, 1954). In the case of soils and industrial powders, it is usually determined by the capillary rise method or by its close correlation with the Darcy permeability or flow resistance of the material. By the Carmen modification of the Kozney equation (Scheidegger, 1954);

$$
K=\eta^{3}\left(\frac{\mathrm{I}}{5^{2} S^{2}}\right)
$$

where $\mu$ is the dynamic viscosity of the fluid, $K$ is the Darcy coefficient defined in terms of the flow measurements by

$$
K=\frac{Q \mu_{0}}{A_{\mu}}\left(\frac{\Delta p}{\Delta_{1}}\right)^{-1}
$$

where $Q$ is the volume of flow of fluid through a sample of length $\Delta x$ and area $A$ in response to a pressure drop of $\Delta p . \mu_{0}$ is the viscosity at some reference pressure and temperature, generally $0^{\circ} \mathrm{C}$ in the case of air-flow through snow. The air permeability of natural snow has been studied extensively by Bender (1957) among others.

No simultaneous measurements of optical transmissivity and air permeability are available in the literature. The most detailed physical descriptions of the snow samples used for observations on light transmission supply only the density and average grain size estimated by sieve analysis or inspection. Fortunately, the relation between the air permeability and these two parameters has been well established on an empirical basis for natural snow. For snow deposited with little or no wind loading the value of $K$ in $\mathrm{cm}^{2} \mathrm{~s}^{-1}$ bar $^{-1}$

$$
K=3.03 d^{1.63} \eta \times 10^{3}
$$

where $d$ is the mean sieve grain size in mm of snow. Substitution of Equations (4) and (6), and the value of $\mu_{0}=\mathrm{I} 70.8 \mu \mathrm{P}$ into ( $\mathrm{I}$ ) yields the predictive relationship for $\beta$ in $\mathrm{cm}^{-\mathrm{I}}$

$$
\beta=\left[k_{\lambda}^{2}(\mathrm{I}-\eta)^{2}+0.23 k_{\lambda}(\mathrm{I}-\eta) \eta r_{0} d^{-0.82}\right]^{1 / 2} .
$$

Dunkle and Bevans (1956) use a value of 0.018 for $r_{0}$ at all wavelengths, which is based on the index of refraction for ice given by available literature. Direct measurements of the reflectivity of glacier ice for a range of wavelengths in the visible spectrum were made by Sauber in 1938, and are presented in Mantis (195I). These indicate much higher values of from 0.43 to 0.50 over the visual spectrum. These values are probably more relevant to the reflection within a snow cover.

The question of the temperature dependence of $r_{0}$ is unresolved. In succeeding calculations, the value 0.45 is assumed for the wavelengths and temperatures to be considered.

The only data available in the literature on the transmission of monochromatic radiation in uniform natural snow cover for which both grain size and density are explicitly stated are those for a spring snow cover studied by Mellor (1966) and those given by Liljequist (1956) for a fine-grained Antarctic snow layer. Both were rather dense with densities of $0.4^{1} \mathrm{Mg} \mathrm{m}^{-3}$ and $0.43 \mathrm{Mg} \mathrm{m}^{-3}$, respectively. The estimated grain size for the first, however, is $2.0 \mathrm{~mm}$ compared with $0.3 \mathrm{~mm}$ for the Antarctic snow.

Liljequist measured the attenuation of the downward flux of radiation with a selenium cell covered by one of four photographic filters; the values for $\lambda$ at maximum transparency are given in Table I. The spectral response of the cell-filter combination as given in the paper is relatively concentrated, o. 63 to 0.73 for the red filter, but considerably more disperse for the shorter wavelengths. 
TABle I. Comparison OF OBSERVED AND PREDICTED EXTINCTION COEFFICIENTS FROM MEASUREMENTS BY LILJEQUIST (I956)

$\begin{array}{ccccc}\begin{array}{c}\lambda \\ \text { wavelength }\end{array} & \begin{array}{c}\kappa_{\lambda} \times \mathrm{IO}^{4} \\ \text { absorptivity of ice } \\ \mathrm{cm}^{-1}\end{array} & \begin{array}{c}\beta_{\lambda} \\ \text { predicted } \\ \mathrm{cm}^{-1}\end{array} & \begin{array}{c}\beta_{\lambda} \\ \text { observed } \\ \mathrm{cm}^{-1}\end{array} & \beta_{\lambda} / \beta_{\mathrm{obs}} \\ 0.42 & 5.0 & 0.077 & 0.066 & 1.2 \\ 0.52 & 9.5 & 0.110 & 0.083 & 1.3 \\ 0.60 & 20.0 & 0.158 & 0.114 & 1.4 \\ 0.65 & 34.0 & 0.205 & 0.172 & 1.2\end{array}$

This problem is not particularly acute for the blue filter, since the value of $k_{\lambda}$ is relatively insensitive to $\lambda$ in this region, but for the remaining two filters, one would expect erroneous results due to the selective attenuation of the various sunlight components and the non-uniformity of the incident solar spectrum. The observed values of $\beta$ and those predicted from Equation (7) are shown in Table I. The values for the red and the blue filter measurements are within $20 \%$. The greatest deviation, $33 \%$, is for the orange filter $(\lambda=0.595 \mu \mathrm{m})$. The spectral response for this combination extends from $0.5^{\mathrm{I}} \mu \mathrm{m}$ to $0.72 \mu \mathrm{m}$, which encompasses the bulk of the solar spectrum and includes a tenfold increase in $k_{\lambda}$.

Comparison with the data for the one natural snow sample included in Mellor's measurements is disappointing. Equation (7) would predict values of $\beta$ almost an order of magnitude less than those observed, as well as a steady increase in $\beta$ with increasing wavelength, which is not observed in the data. Since the sample was refrozen wet spring snow, it is possible that the structure was so disturbed that the empirical relation given by Equation (6) would no longer apply.

The derivation of Equation (7) seems direct and physically plausible as well as being consistent with the known decrease of attenuation with grain size for a given density. It is obvious that more attenuation measurements are needed for any valid test. These must be with sensors with a narrow and well defined spectral response, and must include measurements of density and either air permeability or grain size.

MS. received 26 June 1969 and in revised form 22 August 1969

\section{REFERENCES}

Bender, J. A. 1957. Air permeability of snow. U.S. Snow, Ice and Permafrost Research Establishment. Research Report 37.

Dunkle, R. V., and Bevans, J. T. 1956. An approximate analysis of the solar reflectance and transmittance of a snow cover. Fournal of Meteorology, Vol. 13, No. 2, p. 212-16.

Fara, H. D., and Scheidegger, A. E. 1961. Statistical geometry of porous media. Journal of Geophysical Research, Vol. 66, No. 10, p. 3279-84.

Kottler, F. 1964. The elements of radiative transfer. Progress in Optics, Vol. 3, p. I-28.

Liljequist, G. H. I 55 . Energy exchange of an Antarctic snow-field. Long-wave radiation and radiation balance (Maudheim, 71 ${ }^{\circ} 3^{\prime}$ S., $10^{\circ} 56^{\prime}$ W.). Norwegian-British-Swedish Antarctic Expedition, 1949-52. Scientific Results, Vol. 2, Pt. IA.

Mantis, H. T., ed. г951. Review of the properties of snow and ice. U.S. Snow, Ice and Permafrost Establishment. Report 4.

Mellor, M. I966. Some optical properties of snow. Union de Géodésie et Géophysique Internationale. Association Internationale d'Hydrologie Scientifique. Commission pour la Neige et la Glace. Division Neige Saisonnière et Avalanches. Symposium international sur les aspects scientifiques des avalanches de neige, 5-10 avril 1965, Davos, Suisse, p. 128-40. Scheidegger, A. E. 1954. Physics of flow through porous media. Toronto, University of Toronto Press. 